\title{
Microwave-assisted polyol synthesis of carbon nitride dots from folic acid for cell imaging
}

\author{
This article was published in the following Dove Press journal: \\ International Journal of Nanomedicine \\ 31 October 2014 \\ Number of times this article has been viewed
}

\author{
Weiwei Guan ${ }^{1, *}$ \\ Wei $\mathrm{Gu}^{2, *}$ \\ Ling $\mathrm{Ye}^{2}$ \\ Chenyang Guo' \\ Su Su' \\ Pinxiang $X u^{1,3}$ \\ Ming Xue ${ }^{1,3}$ \\ 'Department of Pharmacology, School \\ of Basic Medical Sciences, Capital \\ Medical University, Beijing, People's \\ Republic of China; ${ }^{2}$ Department of \\ Chemical Biology, School of Chemical \\ Biology and Pharmaceutical Sciences, \\ Capital Medical University, Beijing, \\ People's Republic of China; ${ }^{3 B}$ Beijing \\ Laboratory for Biomedical Detection \\ Technology and Instrument, Beijing, \\ People's Republic of China \\ *These authors contributed equally \\ to this work
}

\begin{abstract}
A green, one-step microwave-assisted polyol synthesis was employed to prepare blue luminescent carbon nitride dots (CNDs) using folic acid molecules as both carbon and nitrogen sources. The as-prepared CNDs had an average size of around $4.51 \mathrm{~nm}$ and could be well dispersed in water. Under excitation at $360 \mathrm{~nm}$, the CNDs exhibited a strong blue luminescence and the quantum yield was estimated to be $18.9 \%$, which is greater than that of other reported CNDs. Moreover, the CNDs showed low cytotoxicity and could efficiently label C6 glioma cells, demonstrating their potential in cell imaging.
\end{abstract}

Keywords: carbon nitride dots (CNDs), folic acid, photoluminescence, cell imaging

\section{Introduction}

Bioimaging, a process of acquiring and visualizing structural or functional images of living systems down to the molecular level, is of great importance in seeking to reveal, diagnose, or examine diseases. Carbon dots (CDs) have attracted tremendous attentions in bioimaging due to their unique optic characteristics such as tunable emission wavelength and high stability. ${ }^{1,2}$ Most importantly, the CDs are free of heavy metals, avoiding severe environmental and biological incompatibility issues. ${ }^{3,4} \mathrm{Up}$ to now, numerous approaches, such as laser ablation, ${ }^{5}$ electrochemical oxidation, ${ }^{6,7}$ chemical oxidation, ${ }^{8,9}$ thermolysis, ${ }^{10,11}$ and a microwave-assisted method, ${ }^{3,10,12}$ have been developed for the preparation of CDs. Among these approaches, the microwave-assisted method is the most economical and convenient for large-scale production of CDs. However, the quantum yield (QY) of the CDs prepared by the microwave-assisted method is usually not satisfactory. To improve the photoluminescent (PL) efficiency, an additional surface-passivation step is a must. For example, the quantum yield of CDs prepared by microwave-assisted pyrolysis of glycerol was $4.63 \%$, and it increased to $12.02 \%$ after surface passivation. ${ }^{13}$

An alternative strategy to enhance the PL efficiency of CDs is to substitute carbon atoms with heteroatoms, such as nitrogen, sulfur, and silicon. ${ }^{14-16}$ So far, the nitrogen atom has been widely used as a substitution because it has a comparable atomic size for bonding with carbon atoms. For instance, carbon nitride dots (CNDs) were successfully obtained by the carbonization of $\mathrm{CCl}_{4}$ in the presence of 1,2 -ethylenediamine under microwave heating. ${ }^{17}$ As the nitrogen substitution disordered the carbon hexagonal rings and create emission energy traps through the radiative recombination induced by electron-hole pairs, the obtained CNDs emitted blue luminescence upon UV excitation. Nevertheless, the use of $\mathrm{CCl}_{4}$ as the carbon source produces a toxic volatile vapor during microwave heating. Alternatively, CNDs can be fabricated by microwave-assisted pyrolysis of less-toxic organic amines in the presence of acids. ${ }^{18}$
Correspondence: Ming Xue Department of Pharmacology, School of Basic Medical Sciences, Capital Medical University, Youanmen, Beijing 100069, People's Republic of China Tel +861083911520 $\mathrm{Fax}+86$ I08 39II 520 Email xuem@ccum.edu.cn 
The QY of as-prepared CNDs, however, was less than 10\%. Therefore, it remains highly desirable to search for new carbon sources in line with a simple and green synthesis route with an improved PL efficiency.

In the present study, folic acid (FA) molecules containing both carbon and nitrogen atoms were adopted as the precursors to produce blue luminescent CNDs by a one-step microwave-assisted polyol method. ${ }^{19}$ Another important feature of this green and simple approach is that the formation and the functionalization of CNDs were accomplished simultaneously. The surface-functionalized CNDs derived from the carbonization of FA could be obtained within 1 minute and were well dispersed in water. The PL properties of the CNDs were investigated in detail. Moreover, the potential of these blue luminescent CNDs in cell imaging was explored.

\section{Methods}

\section{Synthesis of CNDs}

CNDs were synthesized through a microwave-assisted polyol method. ${ }^{19}$ In brief, $15 \mathrm{mg}$ of FA was first dissolved in $3 \mathrm{~mL}$ of diethylene glycol, followed by addition of $200 \mu \mathrm{L}$ of concentrated hydrochloric acid. After ultrasonication, the mixture was placed at the center of the rotation plate of a domestic $750 \mathrm{~W}$ microwave oven (Glanz, Guangdong, People's Republic of China) and heated for 40 seconds. When cooled down to room temperature, the red-brown suspension was subjected to dialysis against pure water through a dialysis membrane (molecular weight cutoff $=500 \mathrm{Da}$ ) for 3 days. Next, the suspension in the dialysis membrane was vacuumdried and then rinsed with anhydrous ethanol. The purified suspension was centrifuged $(13,000 \mathrm{~g})$ for 15 minutes. Finally, the precipitate was vacuum-dried at ambient temperature to yield CNDs.

\section{Characterization}

The ultraviolet-visible (UV-Vis) absorption spectrum was collected on a UV2550 UV-Vis spectrophotometer (Shimadzu, Japan). The PL emission measurements were performed on an F2500 fluorometer (Hitachi; Japan), with a slit width of $2.5 \mathrm{~nm}$ for both excitation and emission. The excitation wavelength increased by a $20 \mathrm{~nm}$ increment from $320 \mathrm{~nm}$ to $460 \mathrm{~nm}$. The morphology of CNDs were examined by transmission electron microscopy (TEM) on a JEM-2100 microscope (JEOL, Japan) and high-resolution transmission electron microscopy (HRTEM) on a JEM$2100 \mathrm{~F}$ microscope (JEOL), respectively. The accelerating voltage was $200 \mathrm{kV}$ for TEM and HRTEM. The specimen for TEM was prepared by dropping an aqueous dispersion of CNDs onto a copper grid coated with a lacy carbon film and subsequently dried in a vacuum. Zeta potential and size distribution measurements were performed on a ZS90 Zetasizer (Malvern, United Kingdom). The Fourier transform infrared spectrum of CNDs was collected on an IR Prestige-21 spectrophotometer (Shimadzu). The X-ray photoelectron spectroscopy (XPS) spectrum of CNDs was measured on an Axis Ultra Imaging Photoelectron Spectrometer (Kratos, Shimadzu, Japan).

\section{Measurement of QY}

The QY of CNDs was estimated by using quinine sulfate (in $0.1 \mathrm{M} \mathrm{H}_{2} \mathrm{SO}_{4}, \mathrm{QY}=54 \%$ ) as a reference. The absorbance values of CNDs and quinine sulfate were measured at $360 \mathrm{~nm}$, and PL emission spectra of CNDs and quinine sulfate were recorded at an excitation wavelength of $360 \mathrm{~nm}$. The integrated fluorescence intensity is the area under the PL curve in the wavelength range from 380 to $700 \mathrm{~nm}$. Then, the integrated fluorescence intensity against the absorbance was plotted linearly with intercept at zero. The QY of CNDs was then calculated according to the following equation:

$$
\phi_{X}=\phi_{S T}\left(\frac{\operatorname{Grad}_{X}}{\operatorname{Grad}_{S T}}\right)\left(\frac{\eta_{X}^{2}}{\eta_{S T}^{2}}\right)
$$

where the subscripts ST and X denote quinine sulfate and CNDs, respectively, $\Phi$ is the QY, Grad is the gradient from the linear plot of integrated fluorescence intensity versus absorbance, and $\eta$ is the refractive index of the solvent (both are 1.33). In order to minimize the reabsorption effects, the absorbance at $360 \mathrm{~nm}$ in a $10 \mathrm{~mm}$ cuvette was kept below 0.1 .

\section{Fluorescence quenching measurements}

The Stern-Volmer constant, $K_{\mathrm{SV}}$, is related to fluorescence intensities by the following Stern-Volmer equation:

$$
F_{0} / F=1+K_{\mathrm{SV}}[Q]
$$

where the $F_{0}$ and $F$ are the fluorescence intensities in absence and presence of quencher (metal ions), respectively, and $[Q]$ is the concentration of quencher. To explore the effect of metal ions on the PL, various metal ions including $\mathrm{Na}^{+}$, $\mathrm{Ca}^{2+}, \mathrm{Al}^{3+}, \mathrm{Cu}^{2+}$, and $\mathrm{Fe}^{3+}$ were added into aqueous suspension of CNDs. 


\section{Cell culture and viability assay}

Glioma C6 cells were cultured in Dulbecco's Modified Eagle's Medium (HyClone) with high glucose, containing $10 \%$ fetal bovine serum, $100 \mathrm{U} / \mathrm{mL}$ penicillin, and $100 \mathrm{mg} / \mathrm{mL}$ streptomycin at $37^{\circ} \mathrm{C}$ in $5 \% \mathrm{CO}_{2}$ humidified atmosphere.

The cytotoxicity of CNDs was assessed by the MTT [3-(4,5-Dimethylthiazolyl-2)-2,5-diphenyltetrazolium bromide] assay. ${ }^{20}$ The $\mathrm{C} 6$ cells were counted and seeded into 96-well culture plates at a density of $7 \times 10^{4}$ cells/well, then incubated for 12 hours. After the culture medium was removed, CNDs with different concentrations, from $50-300 \mu \mathrm{g} / \mathrm{mL}$, were added into each well and incubated for another 24 hours. The medium was refreshed with $120 \mu \mathrm{L}$ medium containing $20 \mu \mathrm{L}$ MTT $(5 \mathrm{mg} / \mathrm{mL}$ in phosphate-buffered solution) and incubated for additional 4 hours. Finally, all medium was depleted and $150 \mu \mathrm{L} /$ well of dimethyl sulfoxide (DMSO) was added, followed by shaking for 10 minutes. The optical density of each well was immediately measured at $490 \mathrm{~nm}$ on a Model 680 Microplate Reader (Bio-Rad, USA) to assess the cell viability. DMSO and nontreated cells were used as the blank and control groups, respectively. The relative cell viability was expressed as follows:

$$
\text { Cell viability } \%=\frac{\mathrm{Abs}_{\text {sample }}}{\mathrm{Abs}_{\text {control }}} \times 100 \%
$$

where Abs is absorbance.

\section{Confocal microscope}

The $\mathrm{C} 6$ cells were seeded into $35 \mathrm{~mm}$ cell-culture plate and grown for 12 hours. Then, the culture medium was replaced by $1 \mathrm{~mL}$ fresh medium containing $100 \mu \mathrm{g} / \mathrm{mL}$ CNDs. The cells were incubated for another 24 hours. The samples were examined under a Leica confocal laser scanning microscope.

\section{Results and discussion \\ Characterization of CNDs}

Figure 1A shows the TEM image of CNDs, which revealed that these spherical nanoparticles were well separated from each other. The HRTEM image taken from a single CND showed that the size of CNDs was about $4 \mathrm{~nm}$ and that the
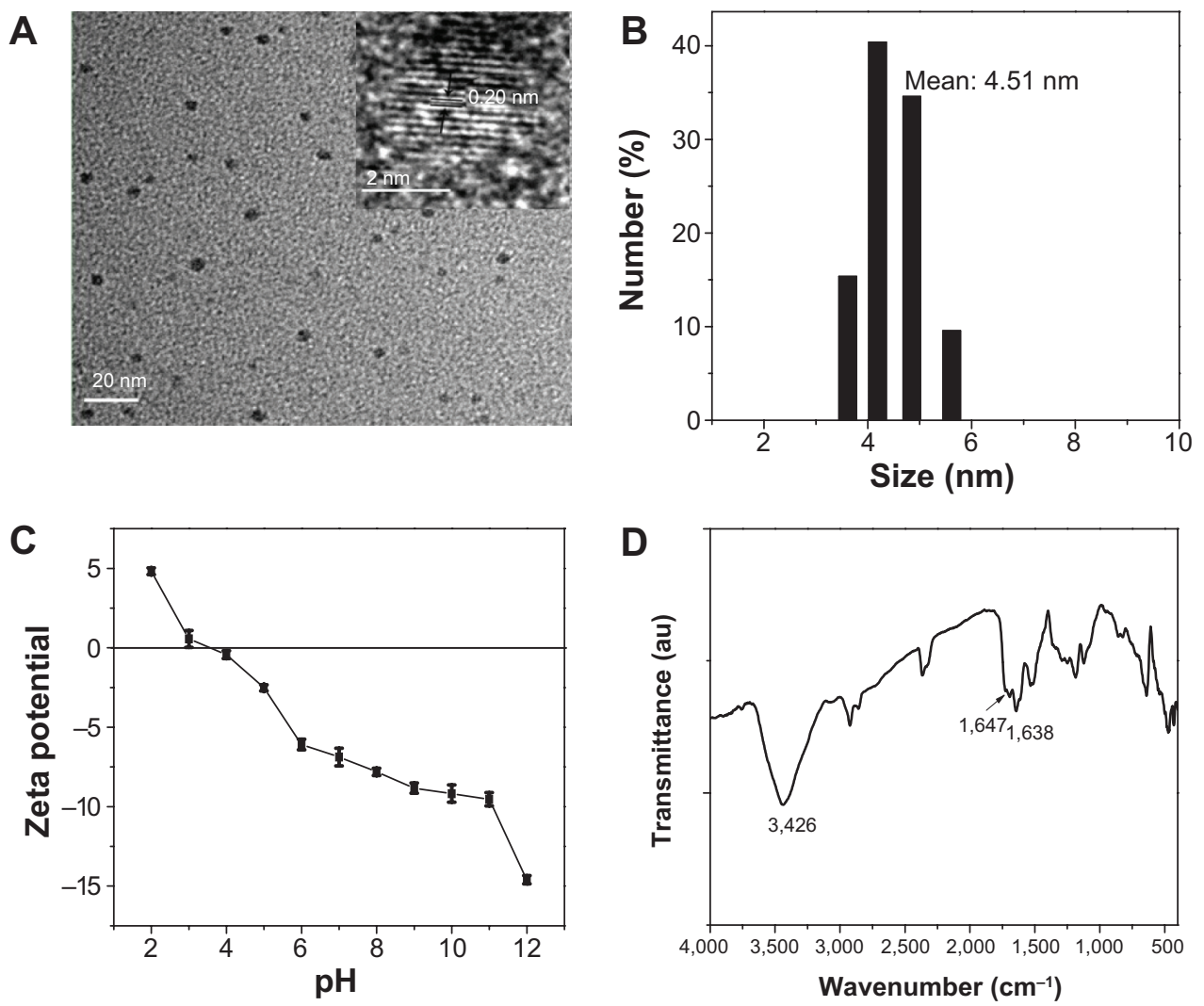

Figure I Characterization of CNDs.

Notes: (A) TEM image of CNDs; scale bar is $20 \mathrm{~nm}$. The inset shows HRTEM image of a single CND; scale bar is $2 \mathrm{~nm}$. (B) Size distribution of CNDs. (C) Zeta potential titration of CNDs. (D) FTIR spectrum of CNDs.

Abbreviations: au, arbitrary units; CND, carbon nitride dot; FTIR, Fourier transform infrared; HRTEM, high-resolution transmission electron microscopy; TEM, transmission electron microscopy. 
lattice spacing was $0.20 \mathrm{~nm}$ (inset, Figure 1A). The corresponding particle size histograms (Figure 1B) further supported that these CNDs had a narrow size distribution of $3.62-5.62 \mathrm{~nm}$ with an average value of $4.51 \mathrm{~nm}$. The zeta potential titration (Figure $1 \mathrm{C}$ ) revealed that zeta potential of CNDs at pH 7.4 was $-7.15 \mathrm{mV}$, suggesting that the surface of CNDs was functionalized with carboxyl groups. As shown in Figure 1D, the characteristic infrared bands of $v(\mathrm{O}-\mathrm{H})$ and $v(\mathrm{C}=\mathrm{O})$ at 3,426 and $1,647 \mathrm{~cm}^{-1}$ confirmed the existence of carboxyl groups on the surface of CNDs. Besides, the band at $1,638 \mathrm{~cm}^{-1}$ assigned to $v(\mathrm{C}=\mathrm{N})$ validated the nitrogencontaining carbon ring.

The composition of CNDs was characterized by XPS. The XPS survey spectrum of CNDs exhibited three peaks at $285.5,399.5$ and $532.5 \mathrm{eV}$, which were attributed to $\mathrm{C} 1 \mathrm{~s}$, $\mathrm{N} 1 \mathrm{~s}$, and $\mathrm{O} 1 \mathrm{~s}$, respectively (Figure 2A). This data indicates that the CNDs were mainly composed of $\mathrm{C}, \mathrm{N}$, and $\mathrm{O}$ atoms. Furthermore, Figure 2B illustrates the XPS spectrum of $\mathrm{CNDs}$ in the $\mathrm{C} 1 \mathrm{~s}$ region. The peak at $286.2 \mathrm{eV}$ revealed the presence of $\mathrm{N}-\mathrm{C}=\mathrm{N}$ (carbon bonded to two nitrogen atoms).

A

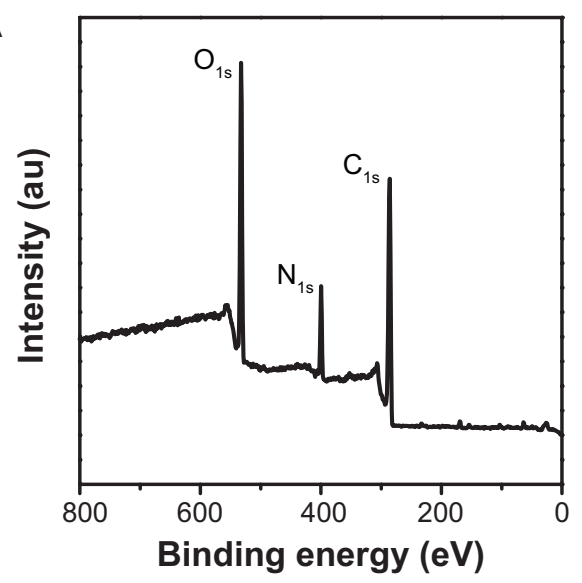

C

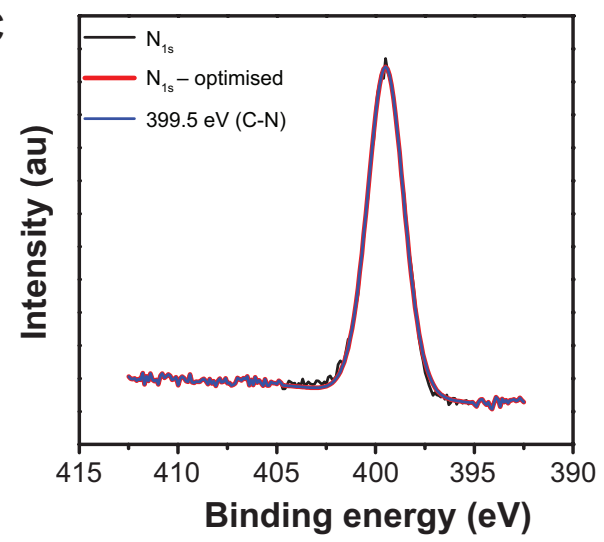

Meanwhile, peaks at 287.7 and $288.8 \mathrm{eV}$ were due to $\mathrm{C}-\mathrm{O}$ and $\mathrm{C}=\mathrm{O} \cdot{ }^{17,18,21}$ The XPS spectrum of CNDs in the $\mathrm{O} 1 \mathrm{~s}$ region showed the peaks at 531.2 and $532.6 \mathrm{eV}$, confirming the presence of $\mathrm{C}-\mathrm{O}$ and $\mathrm{C}=\mathrm{O}$. The $\mathrm{N} 1 \mathrm{~s}$ spectrum (Figure 2C) of CNDs exhibited a sole peak at $399.5 \mathrm{eV}$ associated with $\mathrm{N}-\mathrm{C}=\mathrm{N}$, verifiying the presence of nitrogen in the carbon ring. Note that the N1s spectrum of CNDs differs from that of nitrogen-doped carbon dots, which typically showed N1s peaks originated from $\mathrm{C}_{3}-\mathrm{N}$ and $\mathrm{N}-\mathrm{H}^{22}$

\section{The PL properties of CNDs}

Figure $3 \mathrm{~A}$ presents the UV-Vis absorption and PL emission spectra of the as-prepared CNDs. The UV-Vis spectrum showed an adsorption peak at $270 \mathrm{~nm}$, which was attributed to the $n-\pi *$ transition. The PL emission with a peak at around $460 \mathrm{~nm}$ was observed for the aqueous dispersion of CNDs under excitation at $360 \mathrm{~nm}$, which corresponded to the visible blue color under UV illumination (365 $\mathrm{nm}$ ) as shown in the digital picture (inset, Figure 3a). Using quinine sulfate $(\mathrm{QY}=54 \%)$ as the reference, the QY of CNDs was estimated
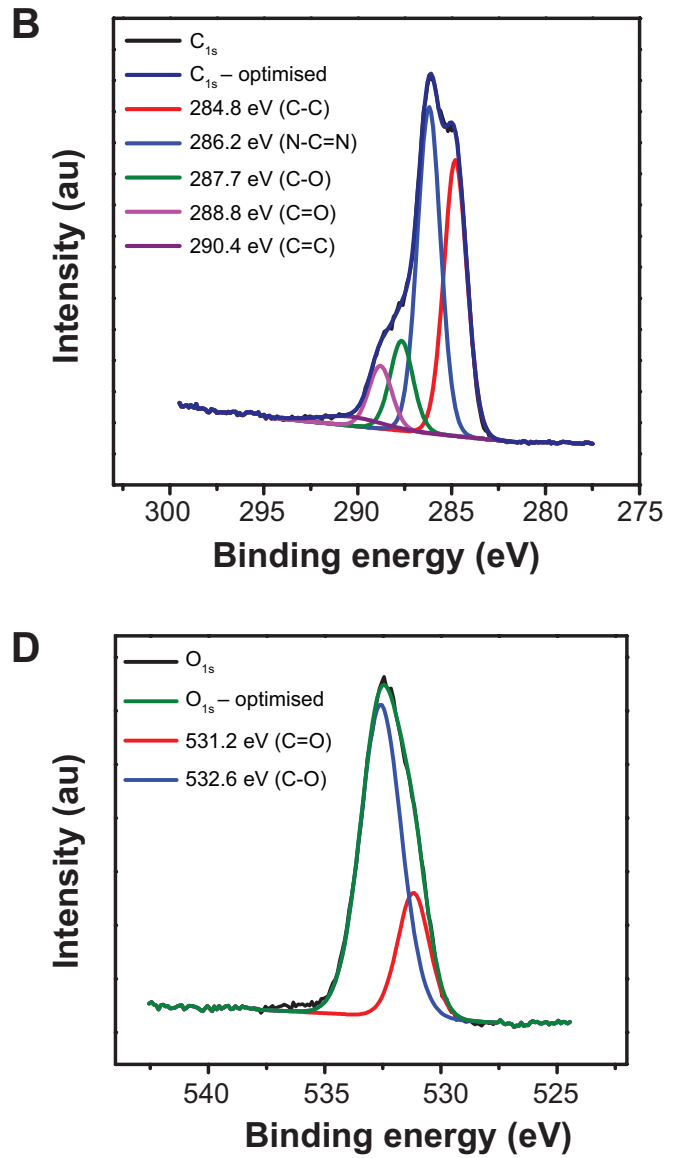

Figure 2 Composition of XPS spectra of CNDs.

Notes: (A) XPS survey spectrum. (B) $C_{1 s}$ XPS spectrum of CNDs. (C) $N_{1 s}$ XPS spectrum of CNDs. (D) $O_{1 s}$ XPS spectrum of CNDs. Abbreviations: au, arbitrary units; CND, carbon nitride dot; XPS, X-ray photoelectron spectroscopy. 
A

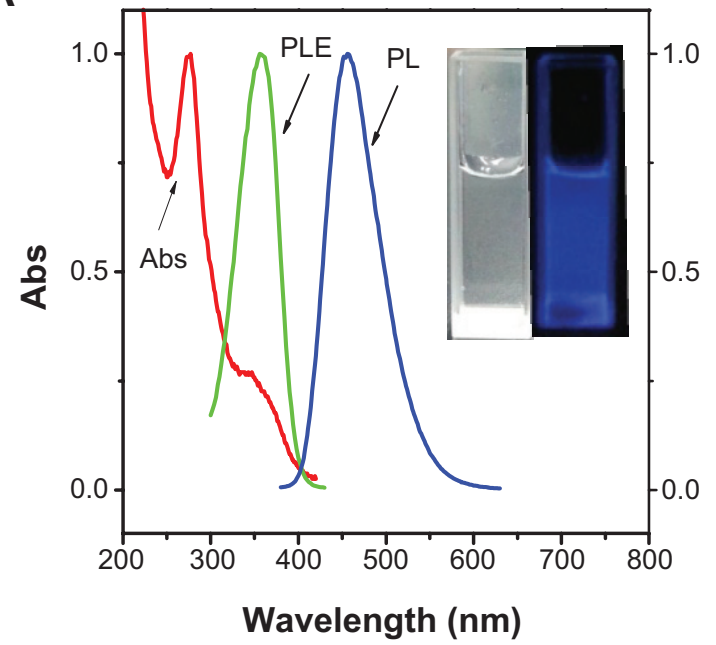

C

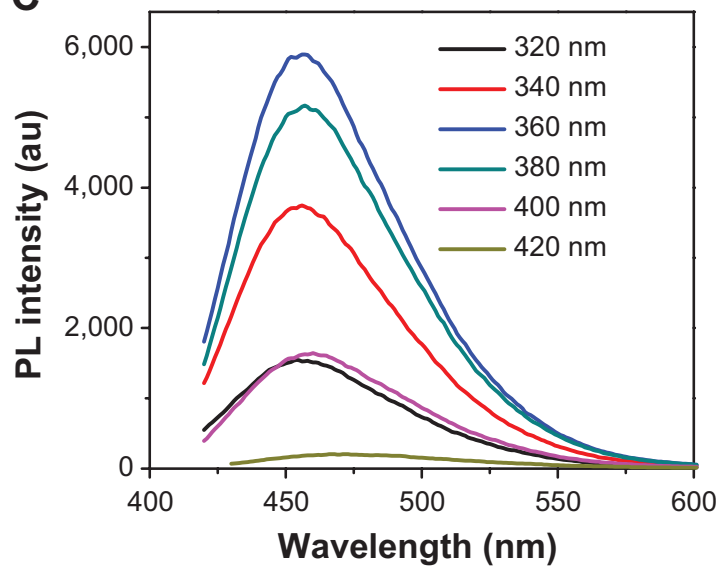

B

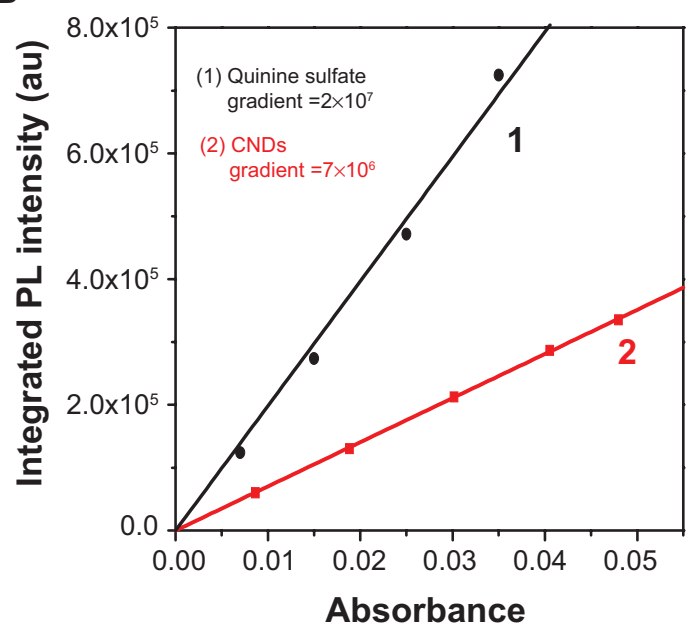

D

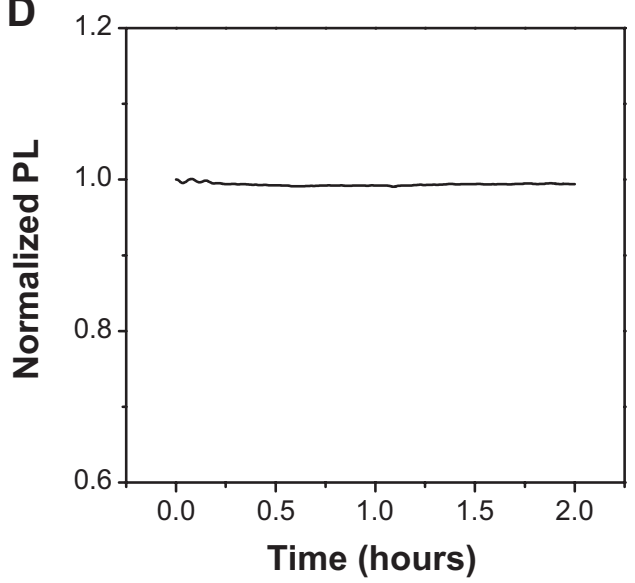

Figure $3 \mathrm{PL}$ properties of CNDs.

Notes: (A) UV-Vis, PL excitation ( $\lambda_{\mathrm{em}}=460 \mathrm{~nm}$ ), and emission $\left(\lambda_{\mathrm{ex}}=360 \mathrm{~nm}\right.$ ) spectra of CNDs (inset: photographs of the CNDs excited by daylight and a $365 \mathrm{~nm}$ UV lamp). (B) QY measurement of CNDs. (C) PL emission spectra of CNDs at different excitation wavelengths. (D) Change of PL intensity of CNDs during a continuous excitation at $360 \mathrm{~nm}$ for 2 hours.

Abbreviations: abs, absorbance; au, arbitrary units; CND, carbon nitride dot; PL, photoluminescent; PLE, photoluminescent emission; QY, quantum yield; UV, ultraviolet; UV-Vis, ultraviolet-visible spectroscopy.

to be $18.9 \%$ (shown in Figure 3B), which is higher than that of other reported CNDs. ${ }^{17,18,23}$

Next, we implemented a detailed study to further explore the PL properties of CNDs by varying the excitation wavelength from $320 \mathrm{~nm}$ to $420 \mathrm{~nm}$ (shown in Figure 3C). Intriguingly, the emission peak remained nearly invariable (at $460 \mathrm{~nm}$ ) and the intensity of PL reached its maximum when the excitation wavelength was $360 \mathrm{~nm}$. As different energy levels are associated with different "surface states" that are responsible for the excitation-dependent-emission, ${ }^{24}$ the observed excitation-independent emission thereby indicates a relatively uniform surface of CNDs. ${ }^{3}$ The wavelengthindependent PL makes the CNDs useful for cell imaging where the autofluorescence could be minimized. Moreover, it was found that these CNDs showed good photostability, as the PL intensity remained almost constant under continuous $360 \mathrm{~nm}$ excitations for up to 2 hours (Figure 3D).

\section{Effect of metal ions and $\mathrm{pH}$ on the PL of CNDs}

Figure 4A shows the change in PL intensity of CNDs upon addition of metal ions. It can be seen that the PL intensity of CNDs is almost unchanged upon addition of $\mathrm{Na}^{+}, \mathrm{Ca}^{2+}$, and $\mathrm{Al}^{3+}$ ions. In contrast, apparent fluorescence quenching was observed upon addition of $\mathrm{Cu}^{2+}$ and $\mathrm{Fe}^{3+}$ ions. Figure 4B indicates the linear fitting of the interaction between CNDs and $\mathrm{Cu}^{2+}\left(\lambda_{\mathrm{ex}}=360 \mathrm{~nm}\right)$ and Figure $4 \mathrm{C}$ shows the linear fitting of the interaction between CNDs and $\mathrm{Fe}^{3+}\left(\lambda_{\text {ex }}=360 \mathrm{~nm}\right)$. The mechanism of fluorescence quenching caused by $\mathrm{Cu}^{2+}$ and $\mathrm{Fe}^{3+}$ ions was then studied according to the Stern-Volmer 
A

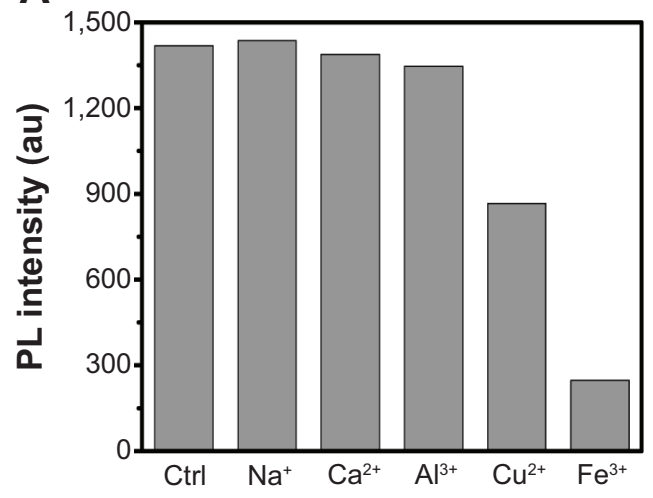

C

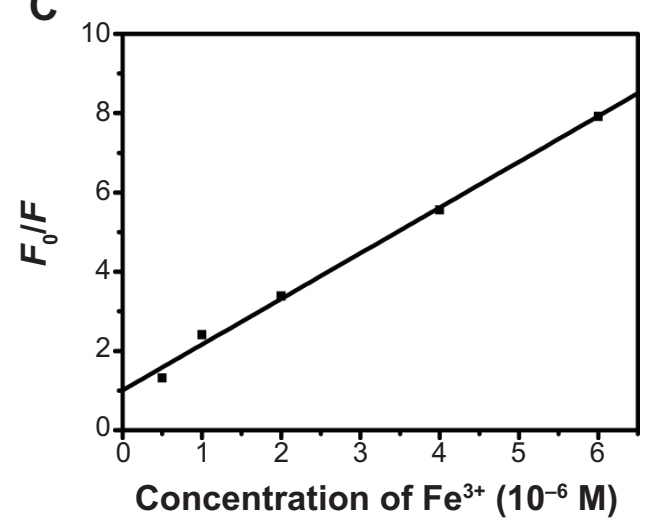

B

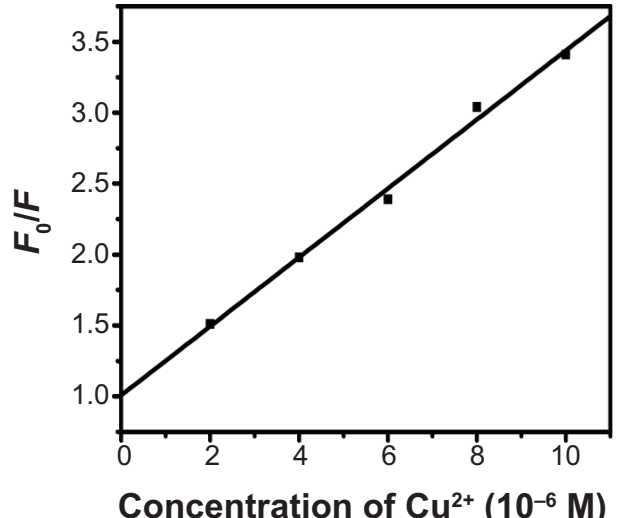

D

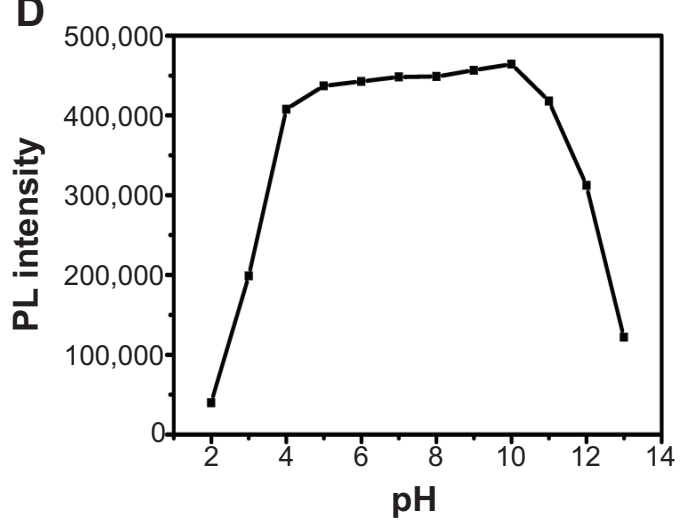

Figure 4 Effect of metal ions and $\mathrm{pH}$ on the PL of CNDs.

Notes: (A) Effect of metal-ions on the PL intensity of CNDs $\left(\lambda_{\text {ex }}=360 \mathrm{~nm}\right)$. (B) Linear fitting of the interaction between CNDs and Cu2 $\left(\lambda_{\text {ex }}=360 \mathrm{~nm}\right)$. (C) Linear fitting of the interaction between CNDs and $\mathrm{Fe}^{3+}\left(\lambda_{\text {ex }}=360 \mathrm{~nm}\right)$. (D) Effect of the $\mathrm{pH}$ on the PL of CNDs $\left(\lambda_{\text {ex }}=360 \mathrm{~nm}\right)$.

Abbreviations: au, arbitrary units; CND, carbon nitride dot; $F_{0} / F$, fluorescence intensities in the absence $\left(F_{0}\right)$ and presence $(F)$ of metal ions; PL, photoluminescent.

equation and it was found that both of them were static quenching, probably due to the formation of coordination bond between the carboxyl groups of CNDs and $\mathrm{Cu}^{2+}$ or $\mathrm{Fe}^{3+}$ ions. The $\mathrm{K}_{\mathrm{SV}}$ were $2.4 \times 10^{5} \mathrm{M}^{-1}\left(\mathrm{Cu}^{2+}\right)$ and $1 \times 10^{6} \mathrm{M}^{-1}\left(\mathrm{Fe}^{3+}\right)$, respectively. Furthermore, the influence of $\mathrm{pH}$ value on the PL of CNDs was also examined (shown in Figure 4D). It was revealed that the $\mathrm{PL}$ of CNDs kept stable in the range of $\mathrm{pH}$ 4-10. However, a significant decrease in the PL intensity was observed when $\mathrm{pH}<4$ and $\mathrm{pH}>10$.

\section{Cytotoxicity and cell imaging}

To assess the cytotoxicity of CNDs, the relative viabilities of $\mathrm{C} 6$ cells exposed to CNDs were measured by the MTT assay. As shown in Figure 5, CNDs showed negligible cytotoxicity toward C6 cells, as cell viability of at least $86 \%$ was retained even though the concentration of CNDs was as high as $300 \mu \mathrm{g} / \mathrm{mL}$ for 24 hours. The confocal laser scanning microscope images clearly evidenced that $\mathrm{C} 6$ cells incubated with CNDs $(100 \mu \mathrm{g} / \mathrm{mL})$ emitted blue luminescence upon excitation at $405 \mathrm{~nm}$, while no fluorescence was observed in the control group (shown in Figure 6). Moreover, it was noted that the emissive CNDs were distributed mainly in the cytoplasm and particularly around the cell nucleus. The luminescence of CNDs in the cell nucleus, however, was relatively weak.

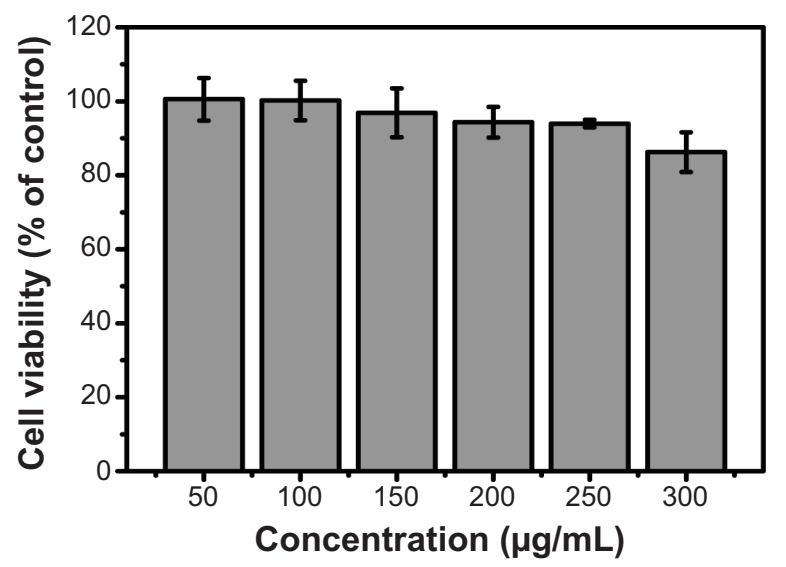

Figure 5 Viability of $\mathrm{C} 6$ glioma cells after 24-hour incubation with CNDs (means \pm $\mathrm{SD}, \mathrm{n}=3$ ).

Abbreviations: CND, carbon nitride dot; SD, standard deviation. 


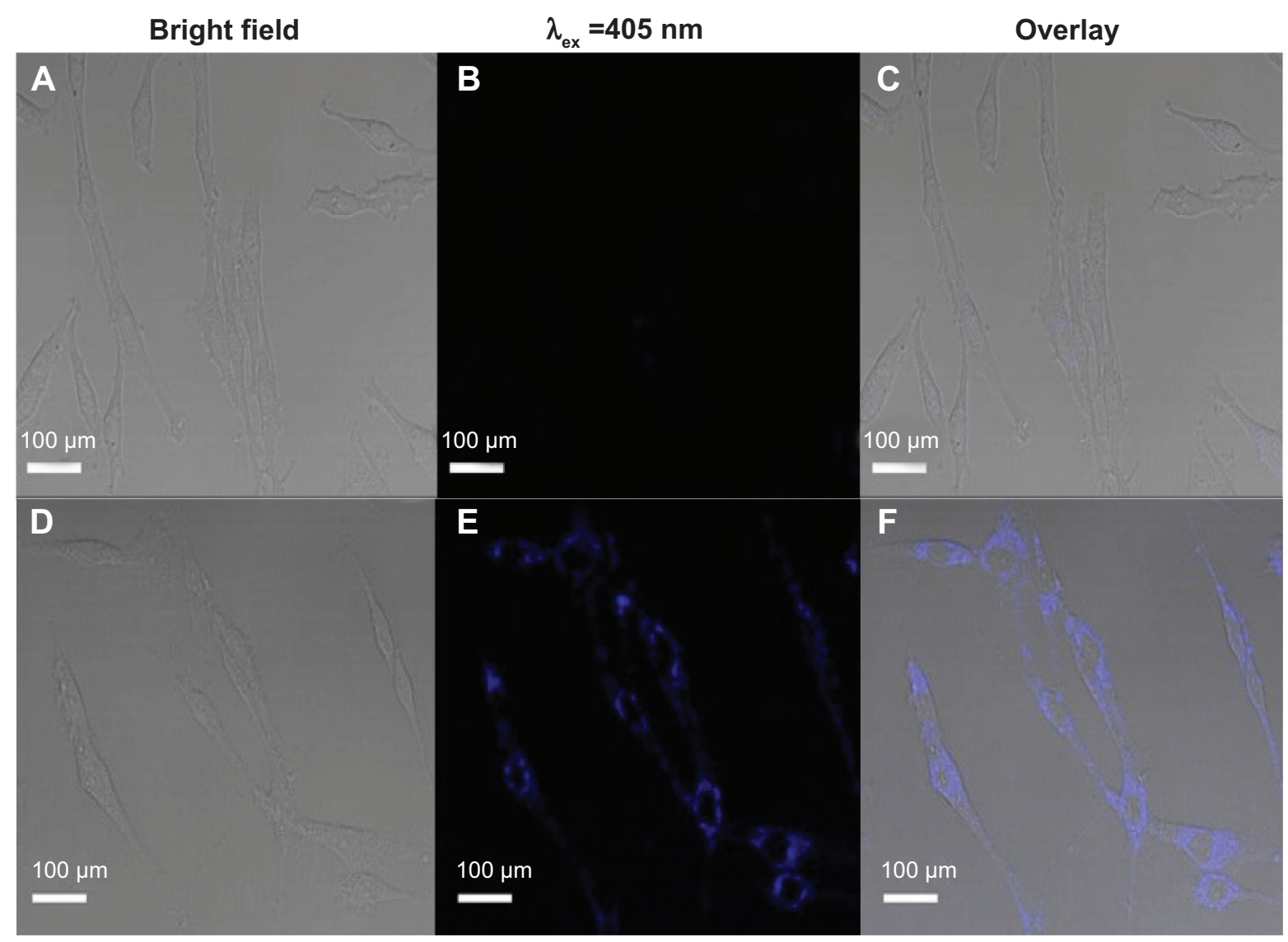

Figure 6 CLSM images of C6 glioma cells.

Notes: (A-C) Without labeling of CNDs. (D-F) With labeling of CNDs. Scale bars: $100 \mu \mathrm{m}$.

Abbreviation: CLSM, confocal laser scanning microscope; CND, carbon nitride dot.

\section{Conclusion}

In summary, blue luminescent CNDs with an improved QY (18.9\%) were successfully prepared by the one-step microwave-assisted polyol method using FA as precursor. The as-obtained CNDs had a narrow size distribution with average diameters of $4.51 \mathrm{~nm}$ and exhibited an excitationdependent emission. Moreover, the CNDs showed low cytotoxicity and could efficiently label the C6 cells, indicating that they are a promising nanoprobe for cell imaging.

\section{Acknowledgments}

The authors thank the National Foundation of Natural Sciences of China (81173121, 81271639), the Key Program of Beijing Natural Science Foundation (KZ201110025024), the Projects for Academic Human Resources Development in Institutions of High Learning (PHR201007111), and Beijing Laboratory for Biomedical Detection Technology and Instrument (PXM2014-014226-000021) under the jurisdiction of Beijing Municipality of the People's Republic of China.

\section{Disclosure}

The authors declare that they have no competing interests in this work.

\section{References}

1. Baker SN, Baker GA. Luminescent carbon nanodots: emergent nanolights. Angew Chem Int Ed Engl. 2010;49(38):6726-6744.

2. Esteves da Silva JCG, Gonçalves HMR. Analytical and bioanalytical applications of carbon dots. Trends Analyt Chem. 2011;30(8):1327-1336.

3. Zhai X, Zhang P, Liu C, et al. Highly luminescent carbon nanodots by microwave-assisted pyrolysis. Chem Commun (Camb). 2012; 48(64):7955-7957.

4. Qiao ZA, Wang Y, Gao Y, et al. Commercially activated carbon as the source for producing multicolor photoluminescent carbon dots by chemical oxidation. Chem Commun (Camb). 2010;46(46):8812-8814.

5. Sun YP, Zhou B, Lin Y, et al. Quantum-sized carbon dots for bright and colorful photoluminescence. J Am Chem Soc. 2006;128(24): 7756-7757.

6. Li Y, Zhao Y, Cheng H, et al. Nitrogen-doped graphene quantum dots with oxygen-rich functional groups. J Am Chem Soc. 2012;134(1):15-18.

7. Lu J, Yang JX, Wang J, Lim A, Wang S, Loh KP. One-pot synthesis of fluorescent carbon nanoribbons, nanoparticles, and graphene by the exfoliation of graphite in ionic liquids. ACS Nano. 2009;3(8): 2367-2375.

8. Liu H, Ye T, Mao C. Fluorescent carbon nanoparticles derived from candle soot. Angew Chem Int Ed Engl. 2007;46(34):6473-6475. 
9. Tian L, Ghosh D, Chen W, Pradhan S, Chang X, Chen S. Nanosized carbon particles from natural gas soot. Chem Mater. 2009;21(13): 2803-2809.

10. Yang Y, Cui J, Zheng M, et al. One-step synthesis of amino-functionalized fluorescent carbon nanoparticles by hydrothermal carbonization of chitosan. Chem Commun (Camb). 2012;48(3):380-382.

11. Zhu S, Zhang J, Qiao C, et al. Strongly green-photoluminescent graphene quantum dots for bioimaging applications. Chem Commun (Camb). 2011;47(24):6858-6860.

12. Jaiswal A, Ghosh SS, Chattopadhyay A. One step synthesis of C-dots by microwave mediated caramelization of poly(ethylene glycol). Chem Commun (Camb). 2012;48(3):407-409.

13. Liu C, Zhang P, Tian F, Li W, Li F, Liu W. One-step synthesis of surface passivated carbon nanodots by microwave assisted pyrolysis for enhanced multicolor photoluminescence and bioimaging. J Mater Chem. 2011;21(35):13163-13167.

14. Wohlgemuth SA, White RJ, Willinger MG, Titirici MM, Antonietti M. A one-pot hydrothermal synthesis of sulfur and nitrogen doped carbon aerogels with enhanced electrocatalytic activity in the oxygen reduction reaction. Green Chem. 2012;14(5):1515-1523.

15. Li Q, Zhang S, Dai L, Li LS. Nitrogen-doped colloidal graphene quantum dots and their size-dependent electrocatalytic activity for the oxygen reduction reaction. J Am Chem Soc. 2012;134(46):18932-18935.

16. Qian Z, Shan X, Chai L, Ma J, Chen J, Feng H. Si-doped carbon quantum dots: a facile and general preparation strategy, bioimaging application, and multifunctional sensor. ACS Appl Mater Interfaces. 2014;6(9):6797-6805.
17. Liu S, Tian J, Wang L, Luo Y, Zhai J, Sun X. Preparation of photoluminescent carbon nitride dots from $\mathrm{CCl} 4$ and 1, 2-ethylenediamine: a heat-treatment-based strategy. J Mater Chem. 2011;21(32): 11726-11729.

18. Liu S, Tian J, Wang L, Luo Y, Sun X. A general strategy for the production of photoluminescent carbon nitride dots from organic amines and their application as novel peroxidase-like catalysts for colorimetric detection of $\mathrm{H}_{2} \mathrm{O}_{2}$ and glucose. RSC Adv. 2012;2:411-413.

19. Liu Y, Xiao N, Gong N, et al. One-step microwave-assisted polyol synthesis of green luminescent carbon dots as optical nanoprobes. Carbon. 2014;68:258-264.

20. Takahashi S, Abe T, Gotoh J, Fukuuchi Y. Substrate-dependence of reduction of MTT: a tetrazolium dye differs in cultured astroglia and neurons. Neurochem Int. 2002;40(5):441-448.

21. Barman S, Sadhukhan M. Facile bulk production of highly blue fluorescent graphitic carbon nitride quantum dots and their application as highly selective and sensitive sensors for the detection of mercuric and iodide ions in aqueous media. J Mater Chem. 2012;22(41):21832-21837.

22. Yang Z, Xu M, Liu Y, et al. Nitrogen-doped, carbon-rich, highly photoluminescent carbon dots from ammonium citrate. Nanoscale. 2014;6(3):1890-1895.

23. Liu S, Wang L, Tian J, et al. Acid-driven, microwave-assisted production of photoluminescent carbon nitride dots from N, N-dimethylformamide. RSC Adv. 2011;1(6):951-953.

24. Tang L, Ji R, Cao X, et al. Deep ultraviolet photoluminescence of water-soluble self-passivated graphene quantum dots. ACS Nano. 2012;6(6):5102-5110.
International Journal of Nanomedicine

\section{Publish your work in this journal}

The International Journal of Nanomedicine is an international, peerreviewed journal focusing on the application of nanotechnology in diagnostics, therapeutics, and drug delivery systems throughout the biomedical field. This journal is indexed on PubMed Central, MedLine, CAS, SciSearch ${ }^{\circledR}$, Current Contents ${ }^{\circledR} /$ Clinical Medicine,

\section{Dovepress}

Journal Citation Reports/Science Edition, EMBase, Scopus and the Elsevier Bibliographic databases. The manuscript management system is completely online and includes a very quick and fair peer-review system, which is all easy to use. Visit http://www.dovepress.com/ testimonials.php to read real quotes from published authors. 